\title{
The effect of parametric excitation on a dynamic system of cutting process
}

\author{
Pham Dinh Tung*, and Nguyen Dong Ahn \\ Department "Aerospace technology and equipment", Le Quy Don Technical University, Hanoi, \\ Vietnam
}

\begin{abstract}
The problem of ensuring stability of movements of the tool about workpiece taking into account parametric self-excitation is considered. The factors causing periodic changes of parameters in dynamic system when cutting are analyzed. They are connected with spatial anisotropy of properties of elasticity in a subsystem of the processed workpiece with allowance variations on workpiece rotation perimeter, with kinematic perturbation from mechanical part of drives of executive elements of the machine, with periodic processes in a cutting zone. The generalized dynamic model of system with periodically changing parameters is given. Influence of periodically changing parameters on stability of trajectories is studied. The features of loss of stability specific to dynamic systems of cutting are disclosed. In particular, it is shown that due to parametrical effects with increasing cutting speed at increase of rotational frequency of spindle there is always a critical frequency at which the system loses stability.
\end{abstract}

\section{Introduction}

Ensuring stability of stationary movements of the tool about workpiece is one of the most important problems at a choice of technological parameters and design features of subsystems of the tool and workpiece, which interact through cutting process. The vibrations arising at loss of stability of a stationary trajectory of movements of the tool about workpiece directly influence geometrical indicators of quality of a detail, productivity, cost of production of details and resistance of the tool. Therefore there are a lot of published works in which the main attention was paid to studying of conditions of loss of stability and the reasons of emergence of self-oscillations when cutting [1-36]. In these works systems of the linear or nonlinear differential equations of dynamics with constant parameters as mathematical models were used.

Generalizing the material given above it should be noted the following directions explaining loss of stability and development of self-oscillations when cutting.

-Loss of stability depends on delay of variations of cutting force in relation to variations of the area of the cut-off layer. Including, existence of delay of cutting forces in relation to deformation shifts of the tool about workpiece is prescribed based on explanation of loss of

\footnotetext{
* Corresponding author: phamdinhtung@mail.ru
} 
stability. These are works of Kudinov A.V., Eliasberg M.E., Zharkov I.G., et al. [1-3,9-11]. The impact of variations in the shear layer on the previous turnover is considered as a retarded argument. These are works of Y. Altintas, S. A. Tobias, H.E. Merritt, J.Tlusty et al. [4-6,20-25,27-30,32-36].

-Loss of stability and development of self-oscillations is explained by dependence of cutting force on cutting speed. Such mechanism of excitation of oscillation was considered in works of Peters, J., I. Grabec, Wiercigroch, M., Kashirin A. I., L. S. Murashkin, et al. $[7,8,12-16,26,31]$.

-Loss of stability and development of self-oscillations is explained by ambiguity of dependence of cutting forces at the movement of the tool towards workpiece and from it. The hysteresis characteristics considered in this case define spatial delay. This mechanism of formation of self-oscillations is stated in works of N.V. Vasilenko, V.A. Ostafiev, T.P. Putyata, A.P. Sokolovskiy et al. [17-19].

There are researches in which the question of loss of stability of system when cutting due to periodic changes of its parameters is considered. These are works of T. Insperger, G. Stepan, Yao, Z., Kopelev Yu.F. et al [37-40]. The changing rigidity is the main reason for parametrical oscillation when cutting. In these works the modified Mathieu-Hill equation actually is considered. The main shortcomings of the given models is their scalar representation which isn't allowing to consider various factors causing periodic changes of parameters of system.

In the present article the specified ideas of dynamics of cutting process are developed, the main attention is paid to the analysis of those factors causing parametrical oscillation and on the basis of what the generalized mathematical model of system with the changing parameters is given and studying of influence of periodic changes of parameters on stability of movements of system is executed. Processing by turning is considered as an example.

\section{The generalized mathematical model of dynamics of cutting process as systems with periodic changes of parameters}

We will give the main physical assumptions accepted at creation of mathematical model.

1. We will consider that the equation of dynamics of cutting process represents the twomass mechanical system consisting of two subsystems of the tool and workpiece. These subsystems interact among themselves through the dynamic link formed by cutting process [2-3].

2. Elastic deformation shifts $X^{(1)}(t)$ of tool subsystem are considered in space рассматриваются в пространстве, that is $X^{(1)}(t)=\left\{X_{1}(t), X_{2}(t), X_{3}(t)\right\}^{T}$, where, $X_{1}(t)$ tangential, $X_{2}(t)$ - radial, $X_{3}(t)$ - axial. Elastic deformation shifts $X^{(2)}(t)=\left\{X_{4}(t), X_{5}(t)\right\}^{T}$ of workpiece subsystem - in the plane normal to its axis of rotation (Fig.1). $X_{4}(t)$ - tangential, $X_{5}(t)$ - radial. We will neglect tortional oscillatory movements of workpiece.

3. At disclosure of regularities of formation of cutting forces we will take the following hypotheses into account [2,24,41 etc.]:

a) Forces formed in cutting zone are proportional to the cross-sectional area of uncut chip (Fig.2), that is

$$
F_{0}(t)=\sigma \cdot S(t)
$$

where $\sigma$ - specific force of cutting; $S(t)=a(t) \cdot h(t)$ - the current value of the cross-sectional 
area of uncut chip; $a(t)=\frac{t_{c}(t)}{\sin \varphi}$ - the current value of width of the cut-off layer; $h(t)=f_{c}(t) \sin \varphi$ - the current value of thickness of the cut-off layer; $\varphi$ - the main angle on the plan; $t_{c}(t)$ and $f_{c}(t)$ - respectively the current value of cutting depth and feed which are defined by the following expressions:

$$
\left\{\begin{array}{l}
f_{c}(t)=f_{c}^{(0)}-X_{3}(t) \\
t_{c}(t)=t_{c}^{(0)}-X_{2}(t)-X_{5}(t)
\end{array}\right.
$$

where $f_{c}^{(0)}=\int_{t-T}^{t} V_{3}^{(0)} d t, t_{c}^{(0)}$ - given values of feed and cutting depth; $V_{3}^{(0)}$ - given speed of feed; $T$ - period of rotation of spindle.

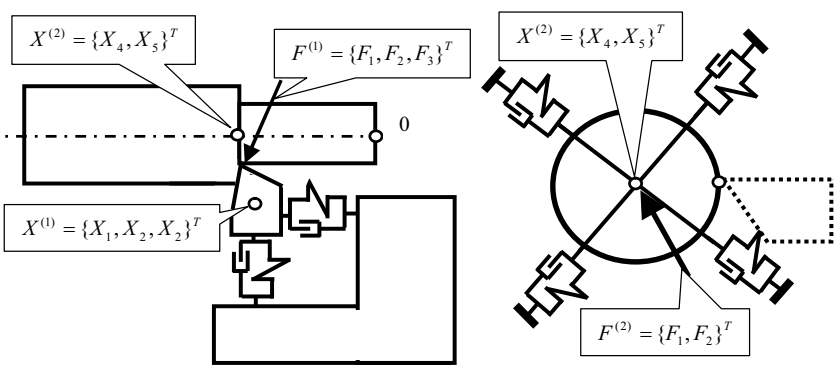

Fig.1. The block diagram of two-mass dynamic system when turning.

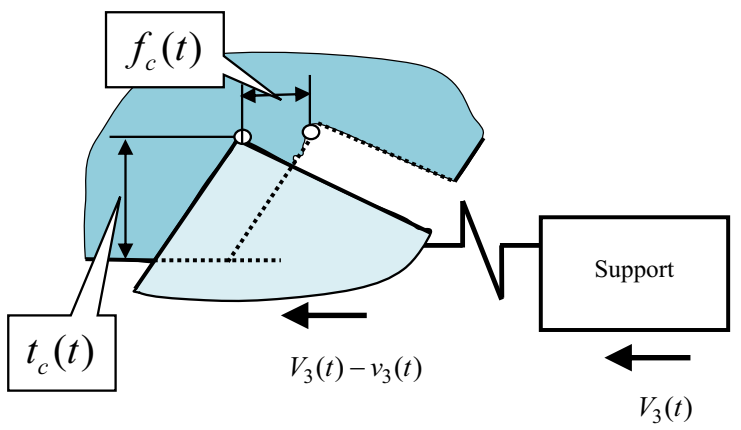

Fig.2. The scheme of formation of the cross-sectional area of uncut chip

b) Cutting forces have invariable orientation in space, that is

$$
F_{i}(t)=\lambda_{i} F_{0}(t), i=1,2,3
$$

where $\lambda_{i}$ - coefficients of orientation of forces in space.

c) The module of force is late at a variation of value of the area of the cut-off layer.

$$
F_{i}(t)=\lambda_{i} \sigma \cdot S(t-\tau)
$$

$\tau$ - delay time or constant of time of a chip formation $[1,9,10]$.

Taking into account the assumptions made the equation of dynamics of cutting process 
has the following form:

$$
\left\{\begin{array}{l}
m_{1} \frac{d^{2} X^{(1)}}{d t^{2}}+c_{1} \frac{d X^{(1)}}{d t}+k_{1} X^{(1)}=F^{(1)}(t) \\
m_{2} \frac{d^{2} X^{(2)}}{d t^{2}}+c_{2} \frac{d X_{2}^{(1)}}{d t}+k_{2} X^{(2)}=F^{(2)}(t),
\end{array}\right.
$$

where $F^{(1)}(t)=\left\{F_{1}(t), F_{2}(t), F_{3}(t)\right\}^{T}$ and $F^{(2)}(t)=\left\{F_{1}(t), F_{2}(t)\right\}^{T}-$ vector - functions of cutting forces.

$m_{1}=\left[\begin{array}{ccc}m_{01} & 0 & 0 \\ 0 & m_{01} & 0 \\ 0 & 0 & m_{01}\end{array}\right], c_{1}=\left[\begin{array}{lll}c_{11} & c_{12} & c_{13} \\ c_{21} & c_{23} & c_{23} \\ c_{31} & c_{32} & c_{33}\end{array}\right], k_{1}=\left[\begin{array}{lll}k_{11} & k_{12} & k_{13} \\ k_{21} & k_{23} & k_{23} \\ k_{31} & k_{32} & k_{33}\end{array}\right]-\quad$ matrixes of inertial,

dissipative and elastic coefficients of tool subsystem; $m_{2}=\left[\begin{array}{cc}m_{02} & 0 \\ 0 & m_{02}\end{array}\right], c_{2}=\left[\begin{array}{cc}c_{02} & 0 \\ 0 & c_{02}\end{array}\right], k_{2}=\left[\begin{array}{cc}k_{02} & 0 \\ 0 & k_{02}\end{array}\right]$ - matrixes of inertial, dissipative and elastic coefficients of workpiece subsystem. As shown in works [1-3], all these matrixes are symmetric positive-definite matrices.

Now we will pass to the analysis of factors which can cause periodic changes of parameters of system (5).

Periodic changes of parameters of the linearized dynamics equation in the vicinity of a stationary trajectory have two main reasons. The first one is periodic change of rigidity in a workpiece subsystem fixed in the chuck. In this case, as shown in experimental studies, values of rigidity of workpiece subsystem in the plane normal to its rotation axis periodically change along rotation angle of workpiece (Fig. 3). In article we will be limited to a case when the detail is fixed in the three-jaw chuck.. Periodic changes of rigidity are caused by that at a workpiece arrangement against the chuck's jaw rigidity is always more, than at its arrangement between jaws. Thus parameters of rigidity of a workpiece subsystem fixed in a spindle in the direction illustrated in Fig. 3 and in the direction orthogonal to it have approximately invariable distributions, but they are shifted on a phase for a three-jaw chuck on a angle of $\frac{\pi}{3}$. It is characteristic that the modulation level of parameters of rigidity of processed workpiece subsystem depends on geometry of jaws and on the way of fixing detail in the back rotating center. Level of modulation is defined by parameter $\mu$ in expression $c(1+\mu \cos 3 \Omega t)$. Besides, frequency $\Omega$ is rotation frequency of spindle. Parameters of rigidity of tool subsystem in two orthogonal directions are symmetric as shown in $[1,6]$. Therefore, matrices of rigidity of workpiece workpiece subsystem can be expressed in the following form:

$$
c=\left[\begin{array}{cc}
c(1+\mu \cos 3 \Omega t) & 0 \\
0 & c\left(1+\mu \cos \left(3 \Omega t+\frac{\pi}{3}\right)\right)
\end{array}\right]
$$

because at symmetric geometry and conditions of fixing any orthogonal system of coordinates is principal one. Here, rigidity of workpiece subsystem is considered in the plane normal to rotation axis of spindle, as rigidity in the direction of rotation rotation axis of spindle is usually bigger by order. 

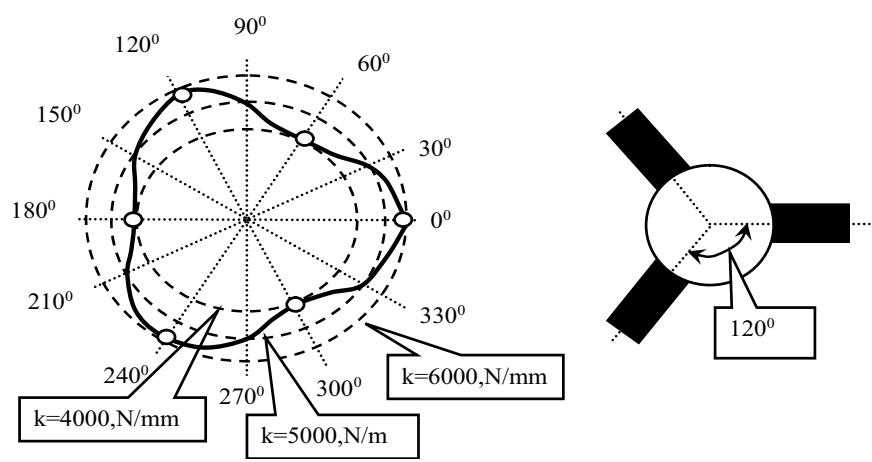

Fig.3. An example of change of rigidity of the workpiece fixed in the three-jaw chuck at change of rotation angle of spindle.

The second reason is caused by the errors of a profile of workpiece cross section caused by inaccuracy of workpiece installation in the tightening device and shift of workpiec axis and its rotation axis. Besides, periodic changes of allowance are influenced by radial beats of spindle which, as shown in work [42], also have circular trajectories in variations relative to ideal rotation axis of spindle. All these errors, which are representable in the form of a limited Fourier serie, cause additional change of the current value of cutting depth, therefore, periodic changes of parameters in the equations of the interacting subsystems. Then the current cutting depth (2) has the following form:

$$
t_{c}(t)=t_{c}^{(0)}+\sum_{i=1}^{N} \mu_{i} \cos (2 i-1) \Omega t-X_{2}(t)-X_{5}(t)
$$

Expression (7) shows dependence of the current cutting depth on deformation shifts taking into account periodic variations of allowance on the workpiece rotation period. In particular, if absolutely round body of workpiece, axis of which is displaced about rotation axis of spindle is considered, then

$$
t_{c}(t)=t_{c}^{(0)}+\mu_{1} \cos \Omega t-X_{2}(t)-X_{5}(t)
$$

First of all, we will give the qualitative characteristic to system (5). It has the stationary solution $X^{*}(t)=\left\{X_{1}^{*}(t), X_{2}^{*}(t), X_{3}^{*}(t), X_{4}^{*}(t), X_{5}^{*}(t)\right\}^{T}$, defined from condition $\frac{d X_{i}}{d t}=0$, $\frac{d^{2} X_{i}}{d t^{2}}=0$. This stationary trajectory can lose stability. To analyze stability of a stationary trajectory of movements of system (5) it is necessary to consider the equation in variations concerning this trajectory. This equation is obtained after replacing variables $X(t)=X^{(*)}(t)+x(t)$ and for small deviations we obtain the equation in variations relative to stationary trajectory:

$$
m_{\Sigma} \frac{d^{2} x}{d t^{2}}+h_{\Sigma} \frac{d x}{d t}+c_{\Sigma} x=0
$$

where $\quad x(t)=\left\{x_{1}(t), x_{2}(t), x_{3}(t), x_{4}(t), x_{5}(t)\right\}^{T}$ - vector variations (deviations) of elastic deformation shifts of system from the stationary; 


$$
\begin{aligned}
& m_{\Sigma}=\left[\begin{array}{ccccc}
m_{01} & 0 & 0 & 0 & 0 \\
0 & m_{01} & 0 & 0 & 0 \\
0 & 0 & m_{01} & 0 & 0 \\
0 & 0 & 0 & m_{02} & 0 \\
0 & 0 & 0 & 0 & m_{02}
\end{array}\right] ; \\
& c_{\Sigma}=\left[\begin{array}{ccccc}
c_{11} & c_{12}-\lambda_{1} \tau f_{c}^{(0)} & c_{13}-\lambda_{1} \tau \sigma\left\{t_{c}^{(0)}+\sum_{i=1}^{i=N} \mu_{i} \cos (2 i-1) \Omega t\right\} & 0 & -\lambda_{1} \tau f_{c}^{(0)} \\
c_{21} & c_{22}-\lambda_{2} \tau f_{c}^{(0)} & c_{23}-\lambda_{2} \tau \sigma\left\{t_{c}^{(0)}+\sum_{i=1}^{i=N} \mu_{i} \cos (2 i-1) \Omega t\right\} & 0 & -\lambda_{2} \tau f_{c}^{(0)} \\
c_{31} & c_{32}-\lambda_{3} \tau \sigma_{c}^{(0)} & c_{33}-\lambda_{3} \tau \sigma\left\{t_{c}^{(0)}+\sum_{i=1}^{i=N} \mu_{i} \cos (2 i-1) \Omega t\right\} & 0 & -\lambda_{3} \tau f_{c}^{(0)} \\
0 & -\lambda_{1} \tau \sigma_{c}^{(0)} & -\lambda_{1} \tau \sigma\left\{t_{c}^{(0)}+\sum_{\substack{i=1 \\
i=N}} \mu_{i} \cos (2 i-1) \Omega t\right\} & c_{02} & -\lambda_{1} \tau f_{c}^{(0)} \\
0 & -\lambda_{2} \tau \sigma f_{c}^{(0)} & -\lambda_{2} \tau \sigma\left\{t_{c}^{(0)}+\sum_{i=1}^{i=N} \mu_{i} \cos (2 i-1) \Omega t\right\} & 0 & c_{02}-\lambda_{2} \tau \sigma_{c}^{(0)}
\end{array}\right] ; \\
& k_{\Sigma}=\left[\begin{array}{ccccc}
k_{11} & k_{12}-\lambda_{1} \sigma_{c}^{(0)} & k_{13}-\lambda_{1} \sigma\left\{t_{c}^{(0)}+\sum_{i=1}^{i=N} \mu_{i} \cos (2 i-1) \Omega t\right\} & 0 & -\lambda_{1} \sigma_{c}^{(0)} \\
k_{21} & k_{22}-\lambda_{2} \sigma_{c}^{(0)} & k_{23}-\lambda_{2} \sigma\left\{t_{c}^{(0)}+\sum_{i=1}^{i=N} \mu_{i} \cos (2 i-1) \Omega t\right\} & 0 & -\lambda_{2} \sigma_{c}^{(0)} \\
k_{31} & k_{32}-\lambda_{3} \sigma_{c}^{(0)} & k_{33}-\lambda_{3} \sigma\left\{t_{c}^{(0)}+\sum_{i=1}^{i=N} \mu_{i} \cos (2 i-1) \Omega t\right\} & 0 & -\lambda_{3} \sigma_{c}^{(0)} \\
0 & -\lambda_{1} \sigma_{c}^{(0)} & -\lambda_{1} \sigma\left\{t_{c}^{(0)}+\sum_{i=1}^{i=N} \mu_{i} \cos (2 i-1) \Omega t\right\} & k_{02}+\mu \cos 3 \Omega t & -\lambda_{1} \sigma_{c}^{(0)} \\
0 & -\lambda_{2} \sigma_{c}^{(0)} & -\lambda_{2} \sigma\left\{t_{c}^{(0)}+\sum_{i=1}^{i=N} \mu_{i} \cos (2 i-1) \Omega t\right\} & 0 & k_{02}+\mu \cos \left(3 \Omega t+\frac{2 \pi}{3}\right)-\lambda_{2} \sigma_{c}^{(0)}
\end{array}\right] .
\end{aligned}
$$

- total matrixes of velocity, inertial and elastic coefficients of dynamic system, respectively.

If in additionally take into account the variations of feed speed, for example, caused by interaction of a support with cutting process, the system (9) still becomes complicated. Assume that trajectory of feed speed is given in the form: $V_{f}(t)=V_{f}^{(0)}+\Delta V_{f}(t)$. We will take into account that the feed value is defined by integrated transformation

$$
f_{c}^{(0)}(t)=\int_{t-T}^{t}\left(V_{f}^{(0)}+\Delta V_{f}(t)\right) d t=f_{c 0}+\Delta f_{c}(t)
$$

where $\Delta f_{c}(t)=\int_{t-T}^{t} \Delta V_{f}(t) d t$ also $T$ - periodic function.

Therefore due to variations of the force component $F_{3}$ change of feed speed takes place. And, these changes have also the period of. Therefore in system (9) additional components in matrixes of velocity coefficients and elasticity, which are periodic with the period of $T$, are formed. Finally, the periodic components of variations of feed speed which aren't connected with periodic changes of allowance value take place. They are caused, firstly, by features of interaction of a support with directing machine through friction unit. Secondly, they are defined by periodically changing errors of production of engagement in mechanical part of the drive, that is all factors influencing machine accuracy. Besides, 
when processing the majority of materials the periodic change of resistance to cutting connected with periodic formation of a surface of sliding in the field of primary plastic deformation takes place. Finally, in principle, many technological modes, for example milling process, have periodic changes of parameters.

It is important to emphasize that the equation in variations about stationary trajectory (9) has the periodic coefficients influencing its stability, that is, they characterize the mechanism for stability loss connected with parametrical excitement which isn't considered earlier in dynamics of machines.

\section{The numerical analysis of stability of cutting system taking into account periodic changes of its parameters}

For studying of influence of periodically changing coefficients on stability of system it is necessary to use Floquet-Lyapunov's theory of the differential equations with periodic coefficients $[43,44]$ including definition of a matrix of a monodromy and the analysis of multiplier of system (9). In the beginning we assume that periodic variations of an allowance are absent and rigidity of tool subsystem much exceeds rigidity of workpiece subsystem. Then the system (9) will be transformed to two scalar subsystems as following:

$$
\left\{\begin{array}{l}
m \frac{d^{2} x}{d t^{2}}+c \frac{d x}{d t}+k(1+\mu \sin \omega t) x=-k_{c} y \\
T \frac{d y}{d t}+y=x
\end{array}\right.
$$

where $k_{c}$ - rigidity of cutting process; $\tau$ - time constant of chip formation. System (11) at $\tau=0$ is Mathieu-Hill's equation. Unlike this equation system (11) when $\mu=0$ can lose stability of balance depending on a ratio of parameters $\tau$ and $k_{c}$ (Fig. 4). We will consider a case, when at these parameters, but at $\mu=0$, the system is asymptotically steady. As well as at research of the Mathieu - Hill's equation, we will enter additional dimensionless parameter into consideration $\eta=\omega / \omega_{0}$, where $\omega_{0}=\sqrt{\left(k+k_{c}\right) / m}$ - eigenfrequency of conservative system at $\mu=0$.

On Fig. 5 the example of change of stability areas in the plane $(\mu, \eta)$ allowing to define depending on $\mu$ critical ranges of rotation frequencies of spindle at which the system loses stability due to parametrical excitement is given. Instability areas on the given illustration are denoted by dot curves. Three provided charts differ in values of a constant of time of chip formation $\tau$, which are shown in Fig. 4 by stars. If $\mu=0$, then at all considered parameters the system is steady. However in process of approach of parameters to border of area of stability, areas of parametrical excitation of system extend and new petals of instability in the field of low frequencies of rotation of spindle are formed. Thus, areas of instability of system due to parametrical excitation depend not only on rotation frequency of spindle and modulation of the rigidity determined by coefficient $\mu$, but also on parameters of a dynamic characteristics of processing.

According to the data provided in works $[1,7,8]$ frequencies of the first forms of oscillation the spindle units of lathes lie in the range $(120-180) \mathrm{Hz}$. For example, with eigenfrequency of the first form of spindle oscillation equal to $\omega_{0}=120 \mathrm{~Hz}$, at a rotation frequency of spindle equal to $2400 \mathrm{rpm}$ the system will lose stability due to parametrical excitation in process of increasing $\tau$ respectively at $\mu=0,5, \mu=0,38$ and $\mu=0,24$. 


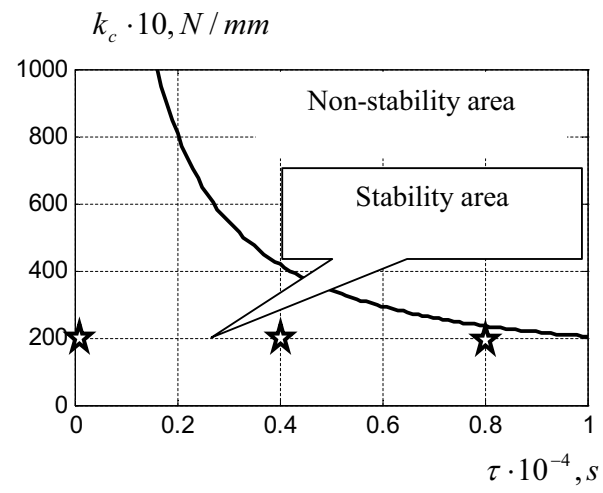

Fig. 4. Stability area in the plane of parameters $\left(\tau, k_{c}\right)$ at $\mu=0$

Generally, if take into account dynamic properties of tool subsystem and take into consideration only the first harmonious component of variations of allowance, then areas of instability extend by bigger level (Fig. 6). Here $\mu, \mu_{1}$ - coefficients of parametrical modulation of correspondingly first harmonious components according to system (9). Matrixes of coefficients of tool and workpiece subsystems are given in Table 1 and 2, respectively. Parameters of a dynamic characteristics of cutting process: $\sigma=3000, \mathrm{~N} / \mathrm{mm}^{2}$; $\lambda=\left\{\lambda_{1}, \lambda_{2}, \lambda_{3}\right\}^{T}=\{0.50,0.70,0.51\}^{T}$. The frequency of the first form of oscillation corresponding to workpiece subsystem is equal $120 \mathrm{~s}^{-1}$.
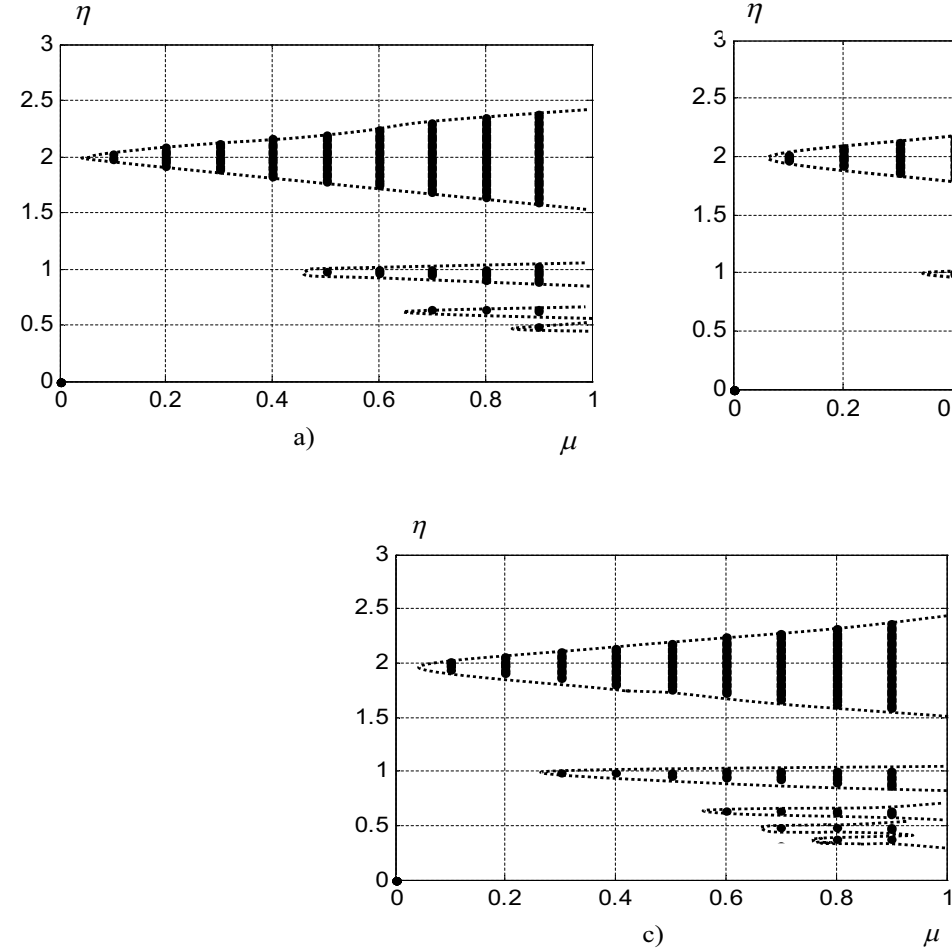

Fig.5. Area of parametrical excitation of system in the plane of parameters $\left(\mu, \eta=\omega / \omega_{0}\right):$ a) $\left.\left.k_{c}=2000, N / m m, \tau=0, s ; b\right)-k_{c}=2000, N / m m, \tau=0.4 \cdot 10^{-4}, s ; c\right)-k_{c}=2000, N / m m$, $\tau=0.8 \cdot 10^{-4}, s$

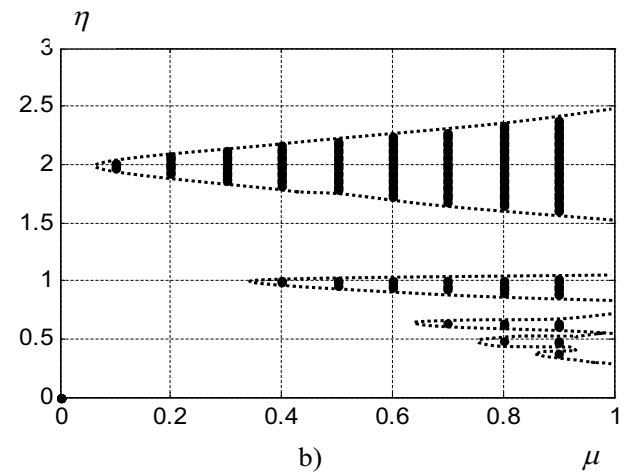


Table 4.1. Parameters of the dynamic subsystem of the tool.

\begin{tabular}{|c|c|c|}
\hline$m_{1} \cdot 10^{-3}, N s^{2} / m m$ & $c_{1}, N s / m m$ & $k_{1}, N / m m$ \\
\hline$\left[\begin{array}{ccc}0.79 & 0 & 0 \\
0 & 0.79 & 0 \\
0 & 0 & 0.79\end{array}\right]$ & {$\left[\begin{array}{ccc}0.16 & 0.03 & 0.02 \\
0.03 & 0.2 & 0.1 \\
0.02 & 0.1 & 0.3\end{array}\right]$} & {$\left[\begin{array}{ccc}10000 & 2000 & 1200 \\
2000 & 21000 & 3100 \\
1200 & 3100 & 25000\end{array}\right]$} \\
\hline
\end{tabular}

Table 4.2. parameters of the dynamic subsystem of the tool.

\begin{tabular}{|c|c|c|}
\hline$m_{2}, N s^{2} / m m$ & $c_{2}, N s / m m$ & $k_{2}, N / m m$ \\
\hline$\left[\begin{array}{cc}0.4 & 0 \\
0 & 0.4\end{array}\right]$ & {$\left[\begin{array}{cc}0.16 & 0.03 \\
0.03 & 0.25\end{array}\right]$} & {$\left[\begin{array}{cc}4000 & 0 \\
0 & 4000\end{array}\right]$} \\
\hline
\end{tabular}

$\eta=\omega / \omega_{0}$

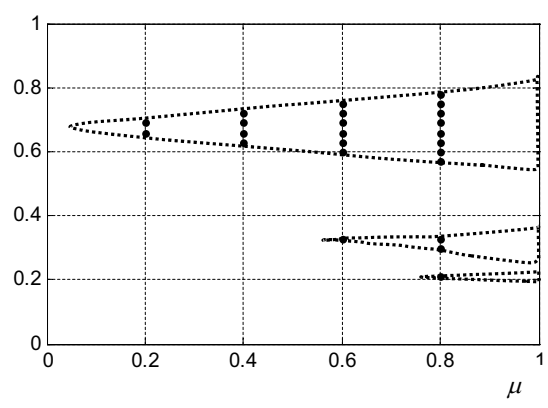

a)

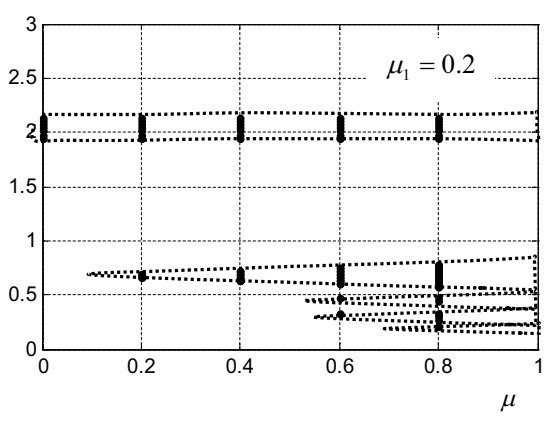

b)

$$
\eta=\omega / \omega_{0}
$$

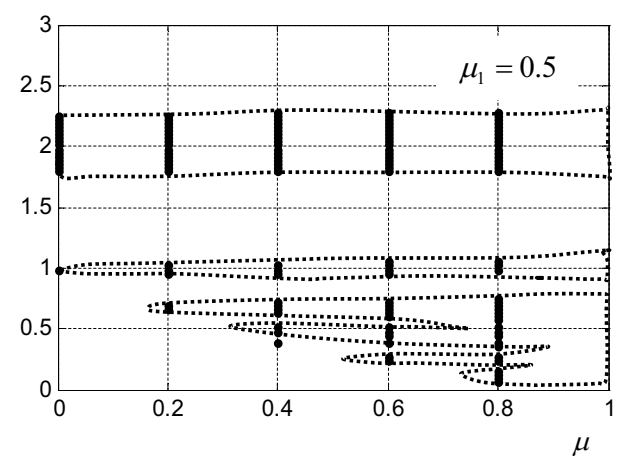

c)

Fig. 6. Areas of parametrical excitation of system when taking into account deformation shifts of the tool and variations of allowance.

Apparently, due to mutual influence of separate forms of oscillation the area of parametrical excitation of oscillation and loss of stability of a stationary trajectory significantly extends, and it is displaced towards low frequencies.

\section{Conclusion}

At certain rotation frequencies of spindle periodic changes of parameters as dynamic characteristics of cutting process due to variation of allowance or due to periodic change of rigidity of a subsystem of the processed workpiece cause loss of stability of cutting process. 
And, areas of loss of stability change at variation of parameters of the dynamic link formed by cutting process. In the considered subject domain this mechanism of loss of stability wasn't taken so far into account. Besides, it should be noted that when studying the kinematic perturbations acting on cutting system it is necessary to consider that these perturbations always cause change of parameters of system. Therefore studying of the parametrical phenomena allows to explain a number of the facts known experimentally, for example, increase in vibrations of the tool concerning workpiece in variations about a balance point after increase of rotation frequency of spindle above some critical value. The given results are of fundamental importance especially in the cases when hight-speed processing by cutting is considered. The given results also show that the reduction of accuracy of the machine connected, for example, with radial beats of spindle expands area of unstable cutting. In the existing ideas of dynamics of cutting process kinematic and other errors of the machine don't influence stability, and the stability area always extends in process of increase in cutting speed that contradicts known experimental results.

\section{References}

1. V.A. Kudinov, Dynamics of machine tools (Publishing house "Engineering" Moscow, 1967) (In Russian).

2. V. L. Zakovorotnyy, M. B. Flek, Dinamika protsessa rezaniya. Sinergeticheskiy podkhod (Terra, Rostov-na-Donu, 2006)

3. V.L.Zakovorotny, A.D. Lukyanov, Dong Anh Nguyen, Pham Dinh Tung, Synergetic system controlled synthesis of dynamics of machine tools, taking into account the evolution of relations (Publishing House DSTU, Rostov-on-Don, 2008) (In Russian)

4. S. A. Tobias, Machine Tool Vibrations (Blackie, London, 1965)

5. H.E. Merritt, J. Eng. Ind, 87 (4), 447 (1965)

6. J. Tlusty, A. Polacek, C. Danek, J. Spacek, Selbsterregte Schwingungen an Werkzeugmaschinen (VEB Verlag Technik, Berlin, 1962)

7. A.I. Kashirin, Issledovaniye vibratsiy pri rezanii metallov (Izdatel'stvo AN SSSR, Moskva, 1944)

8. L.S. Murashkin, S.L. Murashkin, Applied nonlinear mechanics of metal cutting machines (Publishing house "Engineering", Leningrad, 1977) (In Russian)

9. M.Ye. El'yasberg, Avtokolebaniya Metallorezhushchikh stankov (OKBS, SanktPeterburg, 1993)

10. I.G. Zharkov, Vibratsii pri obrabotke lezviynym instrumentom (Mashinostroyeniye. Leningrad Otd-niye, Leningrad, 1986)

11. V.L. Zakovorotnyy, Pham Dinh Tung, Nguyen Suan Tiem, Vestnik DGTU, 11, (8), 1, 1169 (2011)

12. V. Chandrasekharan, S. G. Kapoor, R. E. DeVor, Proc., ASME Sym. On Machining of Advanced Composites, ASME WAM, 33 (1993)

13. M. M. Nigm, M. M. Sadek, S. A. Tobias, Annals of the CIRP, 21, 97 (1972)

14. J. Peters, P. Vanhereck, H. van Brussel, Annals of the CIRP, 20, 129 (1972)

15. H. J. Fu, R. E. DeVor, S. G. Kapoor, ASME J. of Engg. For Ind., 106, 81 (1984)

16. G. Subramani, Suvada, S. G. Kapoor, R. E. DeVor, W. Meingast, Proc., NAMRC, 15, 439 (1987)

17. A.P. Sokolovskiy, Nauchnyye osnovy tekhnologii mashinostroyeniya (Mashgiz, Moscow, 1955) 
18. N.V. Vasilenko, O raschote avtokolebaniy pri rezanii metallov (Prikladnaya mekhanika, Kiev, 1967)

19. T.V. Putyata, V.A. Ostaf'yev, V.I. Akinfiyev, L.YU. Akinfiyeva, Raschot prostranstvennykh avtokolebaniy pri rezanii metallov, 1 (Vestnik mashinostroyeniya, Moscow, 1976)

20. M. Sekar, J. Srinivas, K. Kotaiah, S. Yang, The International Journal of Advanced Manufacturing Technology, 43, 862 (2009)

21. Y. Altintas, M. Weck, CIRP Annals-Manufacturing Technology, 53(2), 619 (2004)

22. M.Wan, Y. Altintas, International Journal of Machine Tools and Manufacture, 87, 16 (2014)

23. Y. Kurata, S.D. Merdol, Y. Altintas, N. Suzuki, E. Shamoto, Journal of advanced mechanical design, Systems, and Manufacturing, 4, 1107 (2010)

24. Y. Altintas, M. Eynian, H. Onozuka, CIRP Annals-Manufacturing Technology, 57, $371(2008)$

25. E. Budak, L.T. Tunc, CIRP Annals-Manufacturing Technology, 59, 403 (2010)

26. I. Grabec, J. Mach. Tools Manufact, 28, 19 (1988)

27. M. Eynian, Y. Altintas, Journal of Manufacturing Science and Engineering, 132, 1 (2010)

28. Y. Altintas, G. Stepan, D. Merdol, Z. Dombovari, CIRP-Journal of Manufacturing Science and Technology, 1, 35, (2008)

29. G. Stepan, Phil. Trans. R. Soc. Lond., A 359 (1781), 739 (2001)

30. T. Insperger, G. Stepan, Periodica Polytechnica, 44, 47 (2000)

31. M. Wiercigroch, A. D.-H. Cheng,. Chaos, Solitons and Fractals, 8, 715 (1997)

32. G. Litak, Chaos, Solitons \& Fractals, 13, 1531-5 (2002)

33. F. C. Moon, T. Kalm'ar-Nagy, Phil. Trans. R. Soc. Lond. A 359, 695 (2001)

34. R. Rusinek, A. Weremczuk, J. Warminski, Mechanics and Mechanical Engineering, 15, 4, 131(2011)

35. B. Balachnadran, Phil. Trans. R. Soc. Lond. A Mathematical Physical And Engineering Science, 359 (1781), 793, 2001

36. L. Vela-Martínez, J. Carlos Jáuregui-Correa, E. Rubio-Cerda, G. Herrera-Ruiz, A. Lozano-Guzmán, International Journal of Machine Tools and Manufacture, 48 (9), 1054 (2008)

37. YU.F. Kopelev, Parametricheskiye kolebaniya stankov (Metallorezhushchiye stanki: resp. mezhved. nauch.-tekhn. Sb., Kiyev, 1984)

38. T. Insperger, G. Stepan, INT J NUMER METH ENG, 61, 117 (2004)

39. G. Stepan et al., Int. J. Bifurc. Chaos, 15, 9, 2783 (2005)

40. Z. Yao, D. Mei, Z. Chen, Journal of Sound and Vibration, 330(13), 2995 (2011)

41. B. Powałka, M. Pajor, S. Berczyński, Advances in manufacturing science and technology, 33, 3 (2009)

42. A. V. Push, Shpindel'nyye uzly. Kachestvo i nadozhnost' (Mashinostroyeniye, Moscow, 1992)

43. E.A. Koddington, N. Levinson, Teoriya obyknovennykh differentsial'nykh uravneniy (IL, Moscow, 1958)

44. I.M. Babakov, Teoriya kolebaniy (Drofa, Moscow, 2004) 